\title{
Advanced extra-uterine pregnancy: A review of the literature
}

\author{
S Ramphal, MB ChB, FCOG (SA); O P Khaliq, PhD; J Moodley, MB ChB, FRCOG, FCOG (SA) \\ Department of Obstetrics and Gynaecology, School of Clinical Medicine, Nelson R Mandela School of Medicine, University of KwaZulu-Natal, \\ Durban, South Africa
}

Corresponding author: S Ramphal (RAMPHALS1@ukzn.ac.za)

Advanced extra-uterine pregnancies, although uncommon, are associated with significant morbidity and mortality. Early diagnosis is essential. A high index of suspicion is necessary and ultrasound examination is probably the most suitable investigative tool to date. Conservative management with the aim of fetal viability in pregnancies $>24$ weeks' gestation is an appropriate form of management and does not adversely affect maternal morbidity and mortality.

Keywords. abdominal pregnancy; advanced extra-uterine pregnancies; conservative management.

S Afr J Obstet Gynaecol 2020;27(3):121-125. https://doi/org/10.7196/SAJOG.2020.v27i3.2029

Advanced abdominal pregnancies, termed advanced extra-uterine pregnancies (AEUP), are those pregnancies situated outside the confines of the uterus after 20 weeks' gestation. They are rare and present in a dramatic manner. ${ }^{[1-3]}$

Although AEUP are rare events in developed countries, they are a common occurrence in developing countries and present a challenge to the diagnostic and clinical management skills of all obstetricians and gynaecologists. ${ }^{[1,2]}$ To date, standardisation of treatment principles, perioperative treatment options, and postoperative management care are lacking and therefore difficult to evaluate scientifically.

AEUP are associated with significant fetal and maternal morbidity and mortality. It has been reported that the risk of dying from an abdominal pregnancy is eight times greater than that from a tubal pregnancy, and 90 times higher than that from a normal term pregnancy. ${ }^{[3]}$ The maternal mortality ranges from $0.5-18 \%$ and the perinatal mortality rate is $40-95 \%{ }^{[4]}$ A review of the literature on AEUP seems appropriate, particularly as recent reports of a conservative approach in the management has resulted in improved fetal survival rates without a concurrent increase in maternal morbidity and mortality. ${ }^{[5]}$

\section{Methods}

We conducted a literature search of all articles in PubMed, Google Scholar and Clinical Keys using the following keywords: abdominal pregnancy and AEUP. Because the condition is rare, the search engines only revealed case reports and case series; there were no systematic reports. Furthermore, grading of the quality of the case reports and case series was not possible.

\section{Incidence of advanced extrauterine pregnancies}

The reported incidence varies and is dependent on a number of factors such as country, antenatal care and the socioeconomic status of the patient. ${ }^{[1-4,6,7]}$ Furthermore, it is more common in countries with high rates of pelvic inflammatory disease, infertility and tubal surgery. Although the risk of having an ectopic pregnancy is rising, the risk of abdominal pregnancy, which is probably always a sequel of a missed ruptured ectopic pregnancy, is apparently declining owing to improved prenatal and early pregnancy care. ${ }^{[7]}$

Maternal age does not appear to be an aetiological factor; ${ }^{[3]}$ however, some studies have reported a higher incidence of abdominal pregnancy in patients of low gravidity, ${ }^{[8,9]}$ but this association has not been demonstrated in other studies. ${ }^{[10]}$

Simultaneous intrauterine and extrauterine pregnancy (heterotopic) is a peculiar type of abdominal pregnancy and is estimated to occur at a frequency of $1 / 30000$ pregnancies. ${ }^{[1]}$ The advent of assisted reproduction techniques may result in the increase of this phenomenon.

\section{Classification}

Although AEUPs are classified into primary or secondary types, this is only of academic interest as it has no bearing on the diagnosis, clinical course and treatment. These pregnancies commonly originate as tubal or ovarian abortions, or rupture of the non-distensible tube with subsequent re-implantation of the conceptus on the peritoneal surface of the abdomen and continuation of the pregnancy. ${ }^{[3,7]} \mathrm{A}$ primary ectopic pregnancy thus becomes a so called 'secondary abdominal' pregnancy. If there is sufficient trophoblastic invasion, continued support of the pregnancy ensues, and the capacious abdominal cavity allows for progression of the pregnancy well into the third trimester. Secondary abdominal pregnancies have also been reported with spontaneous dehiscence of a uterine scar. ${ }^{[12]}$ Uterine perforation during instrumental abortion and after hysterectomy are rare occurrences. ${ }^{[13]}$ Abdominal pregnancy after hysterectomy is thought to contribute to the development of a fistulous tract from the vaginal apex to the peritoneum, or the prolapse of the fallopian tube into the vaginal vault, creating a patent tract for the spermatozoa. ${ }^{[14]}$ The secondary blood supply generally comes from the omentum or the broad ligament.

Primary pelvic peritoneal pregnancies are also rare phenomena; they have been reported to occur with the use of intrauterine contraceptive devices. ${ }^{[15]}$ The criteria for diagnosis of primary pelvic peritoneal pregnancies were established by Studdiford ${ }^{[16]}$ in 1942 and include the following: 
- both ovaries and tubes are normal without signs of recent rupture

- the lack of utero-placental fistula

- the presence of a pregnancy related exclusively to the peritoneal surface and young enough to eliminate the possibility of secondary implantation following a primary nidation in the fallopian tube.

Primary ovarian pregnancy, also a rare entity, is more able to accommodate itself without rupture of the growing pregnancy, and full-term ovarian pregnancies have been reported. ${ }^{[17]}$ Intraligamentous pregnancy occurs when a tubal pregnancy ruptures and grows between the folds of the broad ligaments. ${ }^{[18]}$

A definite differentiation between a primary and a secondary abdominal pregnancy is only possible after a thorough histological examination of the adnexae and uterus, which in most cases is not practical.

\section{Aetiology}

The exact aetiology and pathogenesis of abdominal pregnancies is not known since it has not been possible to establish suitable animal models of pregnancies. However, most abdominal pregnancies result from tubal pregnancies. The aetiological factors are similar to those known for ectopic pregnancies, i.e. tubal surgery and chronic salpingitis.

The past obstetric and gynaecological history is inconclusive in most cases. Previous miscarriages and long-standing infertility were reported to be associated factors, but meta-analyses of patients reported in the literature show that only 60 out of 238 cases of AEUP were associated with tubal abnormalities such as tubal surgery, previous history of ectopic pregnancies, pelvic inflammatory disease and infertility, and four cases had previous spontaneous miscarriages. ${ }^{[6]}$

\section{Diagnosis}

The diagnosis of AEUP is challenging because clinical findings and sonographic features are nonspecific. Most authorities have reported a diagnostic error in the region of $50-90 \%$ in different studies. ${ }^{[3,4,7,10]}$ Diagnosis of AEUP is therefore dependent on a high index of suspicion and factors such as failed induction of labour for intrauterine fetal death. ${ }^{[19,20]}$

Early diagnosis is important to reduce maternal and fetal risks. Obstetrical conditions presenting with signs and symptoms that are difficult to explain, should make one suspicious of AEUP. Because of the atypical presentations, differentiation from abruptio placentae, placenta previa, uterine rupture, post-maturity, ovarian cysts and uterine myoma is challenging. ${ }^{[21]}$
Recurrent abdominal pains in a patient with a history of infertility, tubal surgery or past history of ectopic pregnancies may signal an abdominal pregnancy ${ }^{[2]}$ Table 1 shows a survey of signs and symptoms as reported in a few studies. Vaginal bleeding, recurrent abdominal pains and painful fetal movements are common symptoms. The abdominal pains begin early in the pregnancy and may be due to the transfer of attachment from the tubes to the peritoneal surfaces. The pain is often followed by persistent abdominal discomfort owing to the growing pregnancy in the abdomen and is not infrequently accompanied by gastrointestinal discomfort (indigestion, constipation) or disturbance in urinary function (dysuria, frequency of micturition) owing to irritation of the bladder. Multipara are often aware of the different character of abdominal discomfort and fetal movements as compared with a previous pregnancy. ${ }^{[23]}$ Painful fetal movements, which are thought to be due to the limbs hitting against the abdominal wall, were reported in $40 \%$ of a series of patients. ${ }^{[23]}$

Vaginal bleeding occurred in $9-70 \%$ of patients (Table1). The bleeding is usually dark in color, small in amount, and occurs between 6 - 8 weeks' gestation. It is most probably due to the threatening oncome or rupture of the ectopic pregnancy. In most patients who advance to term, occasional episodes of false labour may occur.

Physical examination is inconclusive in most patients. In a review of 199 reported cases, more than $60 \%$ of all patients had no specific physical finding that led to the diagnosis of AEUP ${ }^{[6]}$ Anaemia occurs frequently, and may be due to tubal abortions and haemodilution. Tenderness, fetal malpresentation, and easily felt fetal parts are warning signs of AEUP. The tenderness is localised to the site of the abdominal pregnancy, particularly when the fetus is dead. Depending on the placental implantation, external palpation of the fetus can be extremely difficult or easy. Common fetal malpresentations are transverse and oblique lies. Table 1 shows the main clinical features reported by authors who reported on case series..$^{[1,2,4,10]}$

\section{Investigations \\ Blood}

Blood investigations in the form of urinary and plasma humanchorionic gonadotrophins, estriol, oestradiol, progesterone, human placental lactogen, Schwangershafts protein-1 (SP1) and alpha-fetoprotein $(\alpha \mathrm{FP})$ are of no diagnostic significance as they correspond to levels found in normal pregnancies. ${ }^{[24]}$ However, placental proteins may be useful in assessing the involution of the placenta left in situ after operative delivery. ${ }^{[25]}$ Elevated maternal serum $\alpha F P$ levels without evidence of a fetal anomaly have been

Table 1. Signs and symptoms from different studies*

\begin{tabular}{|c|c|c|c|c|}
\hline Study & $\begin{array}{l}\text { Maas and Slabber }(N=18),{ }^{[1]} \\
n(\%)\end{array}$ & $\begin{array}{l}\text { Delke et al. }(N=10),{ }^{[4]} \\
n(\%)\end{array}$ & $\begin{array}{l}\text { Rahman et al. }(N=10),{ }^{[10]} \\
n(\%)\end{array}$ & $\begin{array}{l}\text { Ombelet et al. }(N=38),{ }^{[2]} \\
n(\%)\end{array}$ \\
\hline $\begin{array}{l}\text { Abdominal pain and } \\
\text { tenderness }\end{array}$ & $13(72)$ & $10(100)$ & $10(100)$ & $25(65)$ \\
\hline Nausea and vomiting & - & $4(40)$ & $7(70)$ & $7(18)$ \\
\hline Post-maturity & $4(22)$ & - & - & $3(8)$ \\
\hline Vaginal bleeding & - & $7(70)$ & - & $9(23)$ \\
\hline Painful fetal movements & - & - & $4(40)$ & $9(23)$ \\
\hline Easily palpable fetal parts & $3(16)$ & $2(20)$ & $3(30)$ & $12(31)$ \\
\hline Displaced cervix & $6(33)$ & $5(50)$ & $4(40)$ & $18(47)$ \\
\hline
\end{tabular}


reported and are thought to be due to greater transfer of aFP from amnion to maternal serum via the amnion covering the abdominal placenta. ${ }^{[26]}$

\section{Ultrasound}

At present, expertly performed and interpreted ultrasound is the definitive diagnostic technique for the diagnosis of AEUP. ${ }^{[3]}$ Allibone et al. ${ }^{[27]}$ highlighted the following sonographic features:

- a pelvic mass identified as the uterus that is separate from the fetus

- no uterine wall visible between the maternal bladder and the fetus

- placental location outside the confines of the uterine cavity

- fetal parts close to the maternal abdominal wall

- abnormal fetal lie; and

- no amniotic fluid between the placenta and fetal chest or head.

However, these criteria were developed from reported cases diagnosed by both static B-mode equipment and real-time techniques. Now that static techniques have been abandoned and advanced technology has improved ultrasonic resolution, the following criteria are stated to be reliable with real-time sonography: ${ }^{[28]}$

- demonstration of the fetus outside an empty uterus which may be slightly enlarged and displaced

- failure to demonstrate continuity between the cervix and the amniotic cavity

- lack of myometrium tissue surrounding the fetus; and

- demonstration of the posterior uterine wall may be difficult later in pregnancy but is crucial because of the high frequency of implantation in the cul de sac.

The combination of fetal malpresentation, malformations and oligohydramnios should alert the physician of an abdominal pregnancy. Furthermore, oligohydramnios and malformations are postulated to be poor prognostic factors. The outline of the placenta on ultrasound is important when planning incisions for laparotomy as described in a case report by Ombelet et al. ${ }^{[2]}$

A literature search on the efficacy of ultrasound performed on 78 cases showed a diagnostic accuracy of $50 \%(n=39)$ in the diagnosis of AEUP. Ultrasound was either diagnostic or confirmed the diagnosis in $41 \%(n=12)$ of the cases, and was suggestive of AEUP in $9 \%(n=7)$ of the cases. ${ }^{[6]}$

Transvaginal ultrasound may be helpful when abdominal ultrasound is not conclusive. In a case report by Tolefac et al., ${ }^{[29]}$ repeated transabdominal scans missed an AEUP, and transvaginal scan at 25 weeks revealed an empty uterine cavity, a separate mass which was the gestational sac with a fundal implantation. Ultrasound, therefore, is the most important diagnostic tool if the possibility of an abdominal pregnancy is entertained.

\section{Abdominal radiography}

In the pre-ultrasound era, abdominal radiography used to be the only possibility for visualisation of the fetus. Both anteroposterior and lateral X-rays need to be taken to elicit the various signs. ${ }^{[2,3]}$ The fetal skull or other fetal parts may overlap the maternal spine, and extend posterior, as the uterus does not contain them. Of the many radiological signs which have been described, ${ }^{[30]}$ few are conclusive, some are suggestive and others are doubtful or misleading. In current practice, this technique is seldomly used.

\section{Computed axial tomography}

The role of computed axial tomography (CAT) scanning in the management of patients with AEUP is limited. It helps in confirming the diagnosis of AEUP when there are suspicious features on ultrasound, ${ }^{[31]}$ location of the placenta prior to surgery ${ }^{[6]}$, and follow-up of the patients with retained placenta (assessing size and complication).

\section{Magnetic resonance imaging}

Nuclear magnetic resonance imaging (MRI) is a safe method that can provide clear, high-quality images in multiple planes without the use of ionising radiation. It provides easy definition of the placenta, implantation and vasculature. It is also a reliable modality in diagnosing fetal abnormalities and follow-up of placental involution. ${ }^{[32]}$ Its role may be useful in suspected cases of abdominal pregnancy by confirming the exact relationship between the uterus, placenta and fetus, and localisation of the placenta with its vascular supply prior to surgery. ${ }^{[33,34]}$ It has been suggested that in cases of AEUP managed expectantly, periodic MRI can be done to assess integrity of the sac and assist with decision making for early abdominal delivery. ${ }^{[35]}$ However, this has not been scientifically evaluated. A challenge is that in developing countries, this modality is not freely accessible.

\section{Doppler flow studies}

The role of Doppler flow of the umbilical artery in abdominal pregnancy is contentious and remains to be investigated. The blood supply to the placental site is poorer than that of normal intrauterine pregnancies; hence, growth restriction in the fetus is relatively common. Physicians using systolic/diastolic ratios for fetal surveillance and absent ratios as an indication for delivery have been reported. ${ }^{[36]}$

\section{Electronic fetal heart rate monitoring}

Non-stress testing of the fetal heart rate pattern is similar in abdominal pregnancy as in intrauterine pregnancies. ${ }^{[24]}$ The oxytocin challenge test, where the lack of response of myometrium to oxytocin is evaluated, has been used to assist in the diagnosis of an AEUP. However, false positive and false negative results have been demonstrated, making this investigation contentious in contemporary obstetric practice. ${ }^{[37]}$

\section{Fetal and maternal prognosis}

Maternal mortality varies from $0.5-18 \%{ }^{[3,4]}$ High mortality rates may be reduced by timeous diagnosis and interventions. ${ }^{[4]}$ The overall fetal early neonatal death rate varies between $40-95 \%{ }^{[4]}$ Ware $^{[38]}$ reported a perinatal mortality rate of $60 \%$ and a maternal mortality rate of $30 \%$, while Ombelet et al. ${ }^{[2]}$ quoted rates of $76 \%$ and $2 \%$, respectively. It appears that perinatal mortality rates remain high while maternal mortality rates are declining. The improvement of blood transfusion services and newer antibiotics have influenced maternal mortality figures favourably.

The percentage of fetal malformations reported in different studies are variable and ranges from $2-10 \% \cdot{ }^{[3]}$ These malformations are thought to be due to pronounced oligohydramnios in an extra-uterine environment. The most frequently occurring fetal malformations include torticollis, facial asymmetry, malformation of limbs or thorax, and flattening of the fetal head. ${ }^{[2,3,37,38]}$ Pulmonary hypoplasia secondary to oligohydramnios is an important risk factor 
determining the prognosis of the fetus. The neonatal development of newborn infants without malformations is similar to that of intrauterine pregnancies. ${ }^{[39]}$ If the fetus dies intra-abdominally, there is a progressive resorption of the amniotic fluid and sac, with resultant calcification and lithopedian formation, ${ }^{[40]}$ which can be retained for up to 40 years. ${ }^{[4]}$

\section{Management}

The primary objective in the management of AEUP involves a careful and thorough investigation prior to planned definitive surgery. This is best achieved at a referral centres where surgical expertise and neonatal facilities are present. The following factors must be considered:

- maternal comorbidities

- gestational age at presentation

- fetal congenital abnormalities

- fetal viability

- available neonatal facilities; and

- multidisciplinary team.

If the fetus is dead, surgical intervention is generally indicated because of the lack of infection and disseminated intravascular coagulation. In cases in which fetal death is thought to be recent, a more expectant form of management is recommended. This period may range for up to 8 weeks so as to allow for atrophy of the placental vessels. Such expectant management has been reported to decrease intraoperative complications. ${ }^{[42]}$ On the contrary, Maas et al. ${ }^{[1]}$ reported that $90 \%$ of their patients had extrauterine deaths $(n=17 / 18)$, and no vascular complications occurred when laparotomy was undertaken immediately.

If the fetus is alive, most authors advise laparotomy, regardless of gestational age or fetal condition. These authors suggest such management because it is not possible to predict placental separation with subsequent major intra-abdominal bleeding. ${ }^{[21,43]}$

Recent reports appear to take the middle path and adopt an individualised approach. ${ }^{[4,45]}$ If the pregnancy is $<24$ weeks, immediate operative intervention is indicated because of the high risk of maternal morbidity and mortality with poor fetal prognosis if the pregnancy is continued. In patients who present after 24 weeks' gestation, controversy exists in respect to a conservative management approach. Some reports indicate that delayed surgery is successful in allowing fetal maturity and successful maternal and fetal outcomes. It should, however, be recognised that this conservative approach necessitates close and intense fetal and maternal surveillance. In addition, the benefits to the fetus must be weighed against the potential risks to the mother. ${ }^{[5]}$ Those patients for whom a conservative approach has been decided upon, are best kept in a hospital where senior anaesthetic and surgical cover are present, and blood products are readily available, with ready recourse to surgery should the need arise. If the amniotic fluid decreases or becomes absent, pressure deformities and pulmonary hypoplasia become a problem, then immediate delivery is best indicated. ${ }^{[41]}$ Although the aim of conservative management is to prolong the pregnancy to 34 weeks, earlier delivery can be expedited if neonatal facilities can accommodate survival of the newborn.

The surgical management should include the following:

- experienced anaesthetist

- two wide-bore intravenous lines, and adequate supply of compatible blood and blood products
- a surgical team capable of handling bowel and vascular complications

- an experienced paediatrician to accept the neonate in theatre

- knowledge of the placental site; and

- facilities for auto-transfusion.

A midline vertical skin incision is the preferred incision. The extent and length of the incision should be of sufficient size to allow surgical access. The incision on the sac should be made as far as possible from the placental site to avoid problems with the fragile venous sinuses. The delivery of the fetus from the amniotic sac should be carried out cautiously, and should not disturb the placenta and secondary membranes.

\section{Management of the placenta}

The management of the placenta is still a matter of debate, and placental implantation site and surrounding areas must be carefully assessed because of the increased vascularity, even if there is no invasion into major vessels. The placenta in abdominal pregnancy can be attached to important structures such as the small or large bowel, uterus or bladder. Hreshchyshyn et al. ${ }^{[46]}$ studied placental attachments and found that $82 \%$ were attached to the uterus, broad ligament and adnexae, while $12 \%$ were in the upper abdomen. When the placenta is attached to bowel or omentum, careful separation with ligation of vessels is required as attempts with removal could result in catastrophic haemorrhage because of absent uterine musculature that normally contracts the spiral arterioles during the third stage. Some authors recommend angiographic embolisation of the placental vascular supply of placental vessels either prior to surgery or following surgery to decrease intraoperative and postoperative haemorrhage. ${ }^{[47]}$ However, this intervention is not without risks. An attempt at embolisation failed in a patient with a retained placenta, resulting in chronic vascular insufficiency and chronic ischaemia with resultant amputation of the lower limb. ${ }^{[48]}$

\section{Complete removal of placenta}

Complete removal of the placenta usually results in an uncomplicated postoperative recovery period. Factors determining removal are location, blood supply, shape, state of vitality, complications present at the time of surgery and intraoperative bleeding. If the blood supply can be identified, then careful ligation of the feeding blood vessels and removal of the placenta in toto is advised. Hreshchyshyn et al. ${ }^{[46]}$ reported a reduced incidence of re-hospitalisation from $24 \%$ to $0 \%$ and of secondary laparotomy from $40 \%$ to $9.2 \%$ after total removal of the placenta. In exceptional cases, when part of the placenta has separated with intra-abdominal bleeding, temporary clamping or even ligation of important blood vessels, such as the internal ileac artery, can be lifesaving.

\section{Placenta left in situ}

Partial removal of the placenta when its whole blood supply cannot be ligated may result in massive haemorrhage and shock. In such circumstances, it is recommended that the placenta is left in situ and the cord ligated in close proximity to the placenta. ${ }^{[3,4]}$ It should be remembered that the placenta may remain functional for up to 50 days following delivery of the fetus and that its complete absorption is usually completed within 4 months. Ileus, abscess formation, prolonged hospital stay and wound dehiscence are 
reported, which may result in a second operation to remove the placenta. Abdominal sinuses, fever and generalised malaise can occur over a prolonged time. In view of the risk of a 'stormy' postoperative course when the placenta is not removed, methotrexate can be advocated following delivery. Methotrexate results in the destruction of active trophoblastic tissue, thereby reducing the vascularity of the placenta. However, Weinberg et al. ${ }^{[49]}$ questioned the benefits of this treatment in view of the minimal hyperplastic growth of a mature placenta. Furthermore, Rahman et al. ${ }^{[10]}$ stated that the rapid action of methotrexate on placental tissue may result in necrotic tissue becoming infected, resulting in sepsis. ${ }^{[10]}$ Hence, this modality is not recommended as the advantages do not outweigh the risks.

\section{Drains}

Routine drainage of the abdominal cavity is not recommended by most authors because of the fear of introduction of exogenous infection. ${ }^{[10]} \mathrm{A}$ drain can be inserted if haemostasis following removal of the placenta is not absolute. Patients will require antibiotic prophylaxis in this instance. When the placenta is left in situ, prophylactic drainage is contraindicated..$^{[10]}$

\section{Conclusion}

The diagnosis of AEUP requires a high index of suspicion, particularly where induction of labour for an intrauterine fetal death fails. Ultrasound is diagnostic in suspected cases. MRI is a useful adjunct to ultrasound and assists with surgical planning. In pregnancies with diagnosis of AEUP made before 24 weeks' gestation, immediate surgery is recommended. However, in those patients presenting after 24 weeks, an individualised approach with close observation may be practised. In such cases, the benefits to the fetus must be balanced against the potential maternal risks. Methotrexate is not recommended in cases where the placenta is not removed at the time of operation.

\section{Declaration. None.}

\section{Acknowledgements. None.}

Author contributions. Equal contributions.

Funding. None.

Conflicts of interest. None.

1. Maas D, Slabber C. Diagnosis and treatment of advanced extra-uterine pregnancy. S Afr Med J 1975;49(48):2007-2010. https://doi.org/10.1097/00006254-197607000-00009

2. Ombelet W, Vandermerwe J, Van FA. Advanced extrauterine pregnancy: Description of 38 cases with literature survey. Obstet Gynaecol Surv 1988;43(7):386-397.

3. Martin Jr JN, Sessums JK, Martin RW, Pryor JA, Morrison JC. Abdominal pregnancy: Current concepts of management. Obstet Gynaecol 1988;71(4):549-557.

4. Delke I, Veridiano NP, Tancer ML. Abdominal pregnancy: Review of current management and addition of 10 cases. Obstet Gynaecol 1982;60(2):200-204.

5. Hage M, Wall L, Killam A. Expectant management of abdominal pregnancy. A report of two cases. J Reprod Med 1988;33(4):407-410.

6. Costa S, Presley J, Bastert G. Advanced abdominal pregnancy. Obstet Gynaecol Surv 1991;46(8): 515-525. https://doi.org/10.1097/00006254-199108000-00003

7. Atrash HK, Friede A, Hogue C. Abdominal pregnancy in the United States: Frequency and maternal mortality. Obstet Gynaecol 1987;69(3):333-337. https://doi.org/10.3109/00016348509154682

8. Golan A, Sandbank O, Andronikou A, Rubin A. Advanced extra-uterine pregnancy. Acta Obstet Gynaecol Scand 1985;64(1):21-25. https://doi.org/10.3109/00016348509154682

9. Mbura J, Mgaya H. Advanced abdominal pregnancy in Muhimbili Medical centre, Tanzania. Int J Gynaecol Obstet 1986;24(3):169-176. https://doi.org/10.1016/0020-7292(86)90094-9

10. Rahman MS, AL-Suleiman SA, Rahman J, AL-Sibai MH. Advanced abdominal pregnancy observations in 10 cases. Obstet Gynaecol 1982;59(3):366-372.

11. DeVoe RW, Pratt JH. Simultaneous intrauterine and extrauterine pregnancy. Am J Obstet Gynaecol 1948;56(6):1119-1126. https://doi.org/10.1016/s0002-9378(48)90357-3

12. Ramphal SR, Moodley J. Antepartum uterine rupture in previous caesarean sections presenting as advanced extrauterine pregnancies: Lessons learnt. Eur J Obstet Gynaecol Reprod Biology 2009;143(1):3-8 https://doi.org/10.1016/j.ejogrb.2008.11.005
13. Arora V. Abdominal pregnancy following total hysterectomy. Int Surg 1983;68(3):253-255.

14. Babikian S, Thoma DC, Berkey BD. Ruptured ectopic pregnancy presenting 3 years after supracervical hysterectomy. J Ultrasound Med 2008;27(7):1087-1090. https://doi.org/10.7863/jum.2008.27.7.1087

15. Goldman GA, Dicker D, Ovadia J. Primary abdominal pregnancy: Can artificial abortion, endometriosis and IUD be etiological factors? Eur J Obstet Gynaecol Reprod Biology 1988;27(2):139-143. https://doi. org/10.1016/0028-2243(88)90007-x

16. Studdiford WE. Primary peritoneal pregnancy. Am J Obstet Gynaecol 1942;44(3):487-491. https://doi. org/10.1016/S0002-9378(42)90488-5

17. Goyal LD, Tondon R, Goel P, Sehgal A. Ovarian ectopic pregnancy: A 10 years' experience and review of literature. Iranian J Reprod Med 2014;12(12):825.

18. Ade-Ojo IP, Akintayo AA, Afolayan JM, Aduloju OP, Olagbuji BN. Intraligamentary extrauterine pregnancy delivered at term: A case report and review of literature. Afr j Reprod Health 2016;20(1): 104-108. https://doi.org/10.29063/ajrh2016/v20i1.11

19. Lamina M, Akinyemi B, Fakoya T, Shorunmu T, Oladapo O. Abdominal pregnancy: A cause of failed induction of labour. Nigerian J Med 2005;14(2):213-217. https://doi.org/10.4314/njm.v14i2.37183

20. Chun PC, Chua K-H, Shahul Hameed MS, Mathur M, Lee WKR. Undiagnosed abdominal term pregnancy with good neonatal outcome. Case Reports Obstet Gynaecol 2019:2460485. https://doi org $/ 10.1155 / 2019 / 2460485$

21. Harirah HM, Smith JM, Dixon CL, Hankins GD. Conservative management and planned surgery for periviable advanced extrauterine abdominal pregnancy with favorable outcome: Report of two cases. AJP Rep 2016;6(3):e301. http://doi.org/10.1055/s-0036-1588003

22. Alkatout I, Honemeyer U, Noé K-G, et al. Diagnostic and treatment modalities for all localisations of ectopic pregnancy. Int J Women's Health Reprod Sci 2017;5(2):82-89. http://doi: 10.1097/OGX.0b013e31829cdbeb

23. Kilpatrick C, Orejuela F. Approach to acute abdominal pain in pregnant and postpartum women. https:// www uptodate.com (accessed 11 March 2019).

24. Kirkinen P, Lauper U, Huch R, Huch A. Normal placental function and fetoplacental blood circulation in advanced abdominal pregnancy. Acta Obstet Gynaecol Scand 1988;67(3):283-286. https://doi. org/10.3109/00016348809004221

25. Silver RM, Branch DW. Placenta accreta spectrum. N Engl J Med 2018;378(16):1529-1536. http:// doi org/10.1016/.ogc.2015.01.014.

26. Tromans P, Coulson R, Lobb M, Abdulla U. Abdominal pregnancy associated with extremely elevated serum $\alpha$-fetoprotein. Case report. Int J Obstet Gynaecol 1984;91(3):296-298. https://doi. org/10.1111/j.1471-0528.1984.tb04773.x

27. Allibone GW, Fagan CJ, Porter SC. The sonographic features of intra-abdominal pregnancy. J Clin Ultrasound 1981;9(7):383-387. https://doi.org/10.1002/jcu.1870090706

28. Angtuaco TL, Shah HR, Neal MR, Quirk JG. Ultrasound evaluation of abdominal pregnancy. Critical Rev Diagnostic Imaging 1994;35(1):1-59.

29. Tolefac PN, Abanda MH, Minkande JZ, Priso EB. The challenge in the diagnosis and management of an advanced abdominal pregnancy in a resource-low setting: A case report. J Med Case Rep 2017;11(1):1-5. https://doi.org/10.1186/s13256-017-1369-1

30. Sadro C, Bernstein MP, Kanal KM. Imaging of trauma: Part 2, abdominal trauma and pregnancy a radiologist's guide to doing what is best for the mother and baby. Am J Roentgenol 2012;199(6): 1207-1219.https://doi.org/10.2214/AJR.12.9091.

31. Lee LL, McGahan JP. Combined use of ultrasound and computed tomography in evaluation of intraabdominal pregnancy and fetal demise. J Computer-assisted Tomography 1984;8(4):770-771. https:// doi.org/10.1097/00004728-198408000-00036

32. Ramphal S, Moodley J, Rajaruthnam D. Hepatic pregnancy managed conservatively. Trop Doctor 2010;40(2):121-122. https://doi.org/10.1258/td.2009.090218

33. Cohen JM, Weinreb J, Lowe TW, Brown C. MR imaging of a viable full-term abdominal pregnancy. Am J Roentgenol 1985;145(2):407-408. https://doi.org/10.2214/ajr.145.2.407

34. Lockhat F, Corr P, Ramphal S, Moodley J. The value of magnetic resonance imaging in the diagnosis and management of extra-uterine abdominal pregnancy. Clin Radiol 2006;61(3):264-269. https://doi. org/10.1016/j.crad.2005.10.013

35. Rohilla M, Joshi B, Jain V, Gainder S. Advanced abdominal pregnancy: A search for consensus. Review of literature along with case report. Arch Gynaecol Obstet 2018;298(1):1-8. https://doi.org/10.1007/ s00404-018-4743-3

36. Huang K, Song L, Wang L, Gao Z, Meng Y, Lu Y. Advanced abdominal pregnancy: An increasingly challenging clinical concern for obstetricians. Int J Clin Experimen Pathol 2014;7(9):5461. https://doi. org/10.1016/0002-9378(79)90421-6

37. Orr JW, Huddleston JF, Knox GE, Goldenberg RL, Davis RO. False negative oxytocin challenge test associated with abdominal pregnancy. Am J Obstet Gynaecol 1979;133(1):108-110. https://doi. test associated with abdominal

38. Ware HH. Observations on thirteen cases of late extrauterine pregnancy. Am J Obstet Gynaecol 1948;55(4):561-582. https://doi.org/10.1016/0002-9378(48)90111-2

39. Visser A, Venter P. Advanced extra-uterine pregnancy: A case report. S Afr Med J. 1979;56(14):577-578.

40. Mohamed NA, Hajji IA, Omar SA, Kalib KS, Ali AH. Calcified abdominal pregnancy with five years of evolution (Lithopedion): A case report. Open J Obstet Gynaecol 2016;6(8):515-519. https://doi.org/0.4236/ OJOG.2016.68065

41. Santos-Dias A. Advanced abdominal pregnancy: Three cases with a review of the literature. S Afr Med J 1971;45(1).

42. Shelton MG. The treatment of abdominal pregnancies. S Afr Med J 1963;37(22):585-589.

43. National Department of Health. Guidelines for maternity care in South Africa. Pretoria: NDoH, 2015. https://www.kznhealth.gov.za/family/Maternal-Care-Guidelines-2015.pdf (accessed 14 April 2020).

44. National Department of Health. Saving mothers 2011 - 2013: Sixth report on confidential enquiries into maternal deaths in South Africa. Fact sheet. Pretoria: NDoH, 2015. http://www.kznhealth.gov.za/ mcwh/Maternal/Saving-Mothers-2011-2013-short-report.pdf (accessed 14 April 2020).

45. Gülmezoglu AM, Lawrie TA, Hezelgrave N, et al. Interventions to reduce maternal and newborn morbidity and mortality. In: Black RE, Laxminarayan R, Temmerman M, et al., eds. Reproductive, morbidity and mortality. In: Black RE, Laxminarayan R, Temmerman M, et al., eds. Reproductive,
Maternal, Newborn, and Child Health: Disease Control Priorities, 3rd ed. (volume 2). Washington: Maternal, Newborn, and
The World Bank, 2016 .

46. Hreshchyshyn M, Bogen B, Loughran C. What is the actual present-day management of the placenta in late abdominal pregnancy? Analysis of 101 cases. Am J Obstet Gynaecol 1961;81:302-317.

47. Kivikoski AI, Martin C, Weyman P, Picus D, Giudice L. Angiographic arterial embolisation to control hemorrhage in abdominal pregnancy: A case report. Obstet Gynaecol 1988;71(3):456-458

48. Worley KC, Hnat MD, Cunningham FG. Advanced extrauterine pregnancy: Diagnostic and therapeutic challenges. Am J Obstet Gynaecol 2008:198(3):297.e1-e7. https://doi: 10.1016/j.ajog.2007.09.044.

49. Weinberg PC, Pauerstein CJ. Methotrexate and the abdominal placenta. Obstet Gynaecol 1969:33(6):837-841.

Accepted 8 July 202 